\title{
Changements de comportements
}

Colloque des 16 et 17 mars 2006 - Namur, Belgique

Joëlle Van Den Berg

\section{OpenEdition}

Journals

Édition électronique

URL : http://journals.openedition.org/ere/4092

DOI : $10.4000 /$ ere.4092

ISSN : 2561-2271

Éditeur

Centr'ERE

Référence électronique

Joëlle Van Den Berg, «Changements de comportements », Éducation relative à l'environnement [En

ligne], Volume 6 | 2007, mis en ligne le 14 septembre 2007, consulté le 24 septembre 2020. URL:

http://journals.openedition.org/ere/4092 ; DOI : https://doi.org/10.4000/ere.4092 


\title{
Changements de comportements
}

\author{
Colloque des 16 et 17 mars 2006 - Namur, Belgique \\ Joëlle Van Den Berg
}

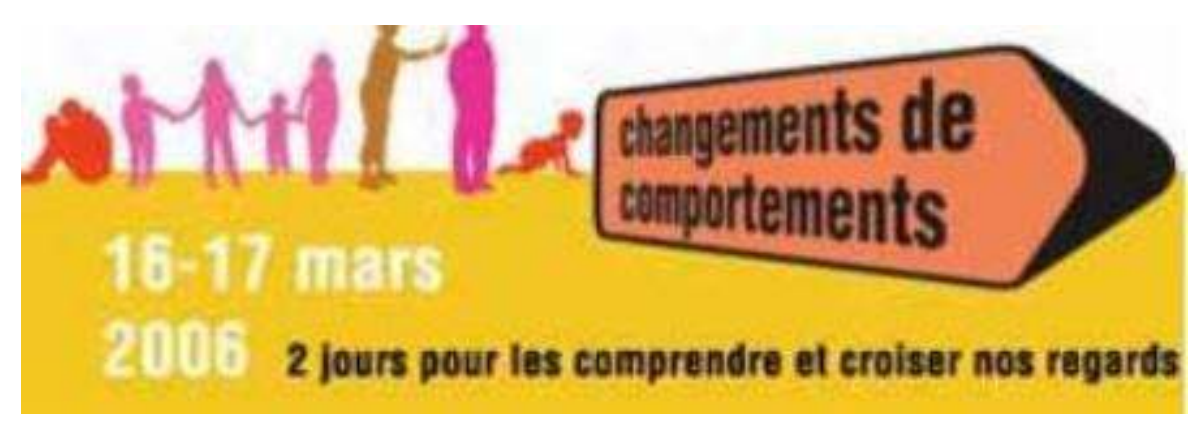

1 Susciter des changements de comportements en vue de permettre un accès juste aux ressources, protéger l'environnement, instaurer un commerce plus équitable, préserver la santé de tous, réduire les inégalités, développer la solidarité entre générations, lutter contre les discriminations et les extrémismes, etc. est au cœur des préoccupations des acteurs de l'éducation à l'environnement, au développement, à la santé, etc. Ces changements vont tous dans le même sens : celui d'un monde plus sain, plus solidaire et plus équitable, au Nord comme au Sud, aujourd'hui comme demain.

2 Mais comment favoriser des changements de comportements? Quel savoir, savoir-faire et faire savoir peut-on mobiliser pour que nos publics changent leurs comportements, qu'ils soient enfants, adolescents, adultes, parents, citoyens, consommateurs, chefs d'entreprise ou décideurs ? Peut-on utiliser d'autres techniques, comme celles du marketing commercial ? Quels outils pouvons-nous développer pour renforcer nos compétences à induire des changements ? Quels sont les ressorts essentiels d'un comportement et de son changement?

C'est pour tenter de répondre à ces questions que ce colloque a été organisé les 16 et 17 mars 2006 à Namur. Il a rassemblé 200 participants venus des quatre coins de la Belgique (et d'ailleurs) et issus d'horizons divers. L'idée de ce colloque est née suite à la venue de Robert-Vincent Joule psychosociologue auteur du «Petit traité de manipulation à l'attention des honnêtes gens » - lors des Rencontres de l'ERE 
(éducation relative à l'environnement) en février 2005. Ce fut un déclic pour approfondir les questions méthodologiques des changements de comportements.

Durant deux jours, les participants au colloque ont pu ainsi entendre et croiser différents éclairages. Celui de la vision systémique avec le psychothérapeute JeanJacques Wittezeale (représentant du Mental Research Institute de Palo Alto) qui nous met en garde : plus ma volonté de changer l'autre est importante, plus j'augmente sa résistance au changement.

5 L'apport de la psychologie sociale avec Vincent Yzerbyt et Olivier Corneille, sur la Théorie du Comportement Planifié (TCP), a démontré notamment que même quand on a l'impression qu'un comportement est le fruit d'une décision bien consciente, analysée, délibérée, les recherches récentes montrent que souvent, les émotions et les affects les influencent.

6 Le deuxième jour, Arnaud Pêtre, expert en "neuromarketing " a perturbé peut-être l'assemblée en analysant le pourquoi et le comment du succès de certains procédés de marketing. Il décrypte quelques grosses ficelles tirées par les pros de la com' et dépeint l'usage que l'associatif pourrait en faire... En tout bien tout honneur. Les nouvelles tendances tenteraient à démontrer tout l'intérêt d'un travail de proximité auquel le monde associatif est attaché. Il aurait par contre à apprendre à mieux communiquer avec sa cible et à « segmenter » son public.

7 D'autre part, au cours de ce colloque, 27 expériences de terrain ont été présentées au cours d'ateliers, avec chaque fois un support d'analyse, s'inspirant de la théorie du comportement planifié le premier jour et de principes du marketing le second (segmenter son public). Les apports théoriques alternant ainsi avec des ateliers pratiques, question de varier nos angles d'analyse et de mieux intégrer les apports théoriques, ceci avec plus ou moins de succès.

8 Enfin, le Worldcafé a permis aux 200 personnes présentes de remuer leurs méninges de manière dynamique en débattant autour de la question : "Comment adapter nos pratiques professionnelles pour favoriser un changement de comportement?»

9 En clôture, le psychopédagogue Jean Therer a réalisé une synthèse sélective des grands thèmes abordés au cours de la rencontre. Ces apports sont-ils compatibles avec les concepts et les pratiques psychopédagogiques ? Comment intégrer ces connaissances dans notre vie quotidienne ? Ce qu'il y avait de particulier à ce Colloque et qui en a peut-être dérouté certains c'est qu'on y a moins parlé du «pourquoi » changer, « quoi changer » que du « comment » changer, et en la matière, du chemin reste à faire !

Plus d'informations sur www.reseau-idee.be/changements-comportements/ (extraits de conférences écrits et audio, documents de références, etc.), sur www.mondequibouge.be (interview des intervenants) ou dans le numéro $70 \mathrm{du}$ magazine Symbioses qui y consacre son dossier (téléchargeable via le site www.reseauidee.be ou à commander). 


\section{AUTEUR}

JOËLLE VAN DEN BERG

Réseau Idée, Information et Diffusion en éducation à l'environnement 